\title{
ЭДЬЮТЕЙНМЕНТ КАК ЕДИНСТВО СОЗНАТЕЛЬНОГО И БЕССОЗНАТЕЛЬНОГО
}

\author{
И. Г. Хангельдиева
}

Московский государственный университет имени М. В. Ломоносова

Аннотация: В статье представлены основные положения эдьютейнмента как особой развлекательной формы образования.

Текст доклада автора на Всероссийской научной конференции «Культура между Логосом и Мифом: к проблеме бессознательного (к 80-летию А. Э. Воскобойникова)», которая прошла в Московском гуманитарном университете 26-27 октября 2017 года.

Ключевые слова: сознательное; бессознательное; эдьютейнмент; философия образования

\section{EDUTAINMENT AS A UNITY OF THE CONSCIOUS AND UNCONSCIOUS}

\author{
I. G. Khangeldiyeva \\ Lomonosov Moscow State University
}

Аннотация: The paper presents the main provisions of edutainment as a special entertaining form of education.

The text of the author's speech at the All-Russian Scientific Conference "Culture between Logos and Myth: on the Issue of the Unconscious (dedicated to the 80th anniversary of A. E. Voskoboynikov)", which was held at Moscow University for the Humanities on 26-27 October 2017.

Ключевые слова: conscious; unconscious; edutainment; philosophy of education

$$
\begin{array}{r}
\text { «Скучные уроки годны лишь на то, чтобы внушить ненависть и к } \\
\text { тем, кто их преподает, и ко всему преподаваемому» } \\
\text { Ж. - Ж. Руссо } \\
\text { «... Индустрия 4.0, цифровая экономика, затрагивают сами основы } \\
\text { того привычного уклада, в котором мы живем» } \\
\text { Дж. Ма }
\end{array}
$$

Единство сознательного и бессознательного сопровождает человека на протяжении всей жизни. Между ними нет непреодолимой границы. Когда мы что-то осваиваем, то акцентируем сознательное отношение к процессу. Однако, овладев навыком, доводим его до автоматизма и в последующем уже не думаем, как его осуществить. Это касается различных сфер: искус- 
Научные труды Московского гуманитарного университета 2018 № 3

ства, науки, спорта, практически любой профессиональной и непрофессиональной деятельности. Образование не является здесь исключением.

В этой области принято традиционно фокусироваться на рациональном начале, которое связывается с активной деятельностью сознания. Нам необходима концентрация сознания при получении новой информации, особенно если она является сложной, чтобы ее осознать и понять. В данном контексте бессознательное чаще всего связывается с неосознаваемыми действиями, а сознательное - с элементами творчества. Бессознательное реализуется не только в инстинктах и автоматических действиях. Оно является следствием того, что человек подавляет в своем сознании некую информацию, вытеснят ее в целях защиты собственного психологического комфорта. Механизмом подобной защиты может быть отрицание, вытеснении, обесценивании, переадресации с себя на другого, подражании кому-либо, или присваивание положения другого, включении в сопереживание, бегство от проблемы... В процессе образования и обучения все эти отрицательные моменты могут присутствовать и блокировать освоение информации.

Современное общество развивается очень динамично, в нем постоянно происходят перемены, которые требуют осознания и принятие нестандартных решений. Реально существует избыточных поток информации. Для того, чтобы он мог оставить след, важно «зацепить» реципиента не только контентом, но и на эмоциональном уровне оригинальной формой и вызвать не просто лояльное, но весьма заинтересованное отношением. Важной задачей становится задача не только «ЧТО» преподавать, но и «КАК».

Неслучайно многие современные исследователи человеческого мышления подчеркивают, что наиболее востребованными к 20-м годам XXI века будут креативность, когнитивная гибкость и эмоциональный интеллект. Эти характеристики не смогут возникнуть на пустом месте, они смогут появляться и развиваться при непосредственном взаимодействии с художественной культурой, но не с ее массовыми версиями, а со сложными художественными текстами и в первую очередь музыкальными и литературными. Именно сложные музыкальные и литературные художественны произведения стимулируют развитие сложнейших нейронных сетей в мозге человека. Вопрос почему - риторический. Именно искусство представляет собой квинтэссенцию творческого процесса в чистом виде. Музыка в данном контексте представляет особый интерес, так как способ ее создания, а затем восприятия и «распаковывания» художественных кодов принципиально отличается от других видов искусства. Музыка, как доказывают последние исследования, усиливает развитие новых нейронных связей в мозге человека, что закономерно способствует развитию творческого начала. Креатив- 
ность без творчества невозможна, эмоциональный интеллект во многом стимулируется под воздействием искусства, как и когнитивная гибкость, о чем уже было сказано выше.

Д. Гоулман - один из авторов книги «Эмоциональное лидерство: искусство управления людьми на основе эмоционального интеллекта» (Гоулмен, Бояцис, МакКи, 2017) отмечает, что эмоциональный интеллект представляет собой умение лидеров управлять отношениями с другими людьми и собственными эмоциональными состояниями.

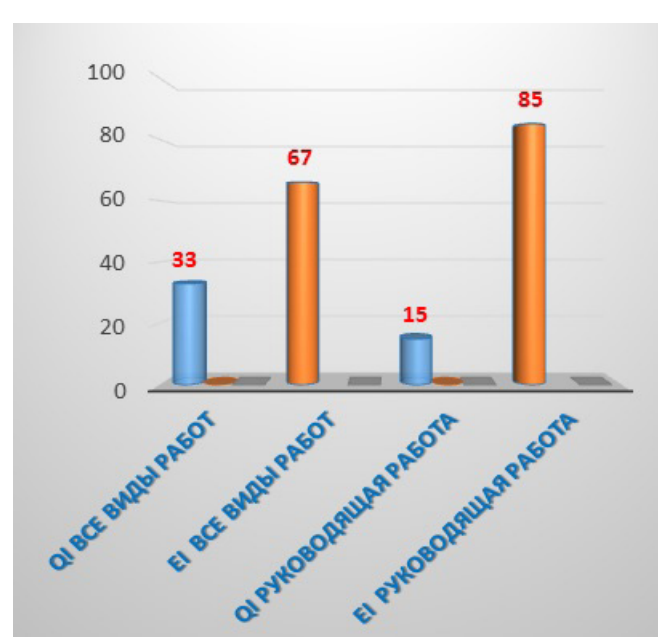

Диаграмма 1.

В диаграмме 1 исследователи эмоционального интеллекта сравнивают его роль и значение с ролью и значение обычного интеллекта по двум позициям: «все виды работ» и «руководящая работа». Из диаграммы очевиден вывод, согласно которого эмоциональный интеллект превышает цифры QI в два раза по всем видам деятельности, а во второй позиции более, чем в 5 раз. Следовательно, роль эмоционального интеллекта для руководителей чрезвычайно важна.

Учеба - это форма интеллектуального труда, в которой присутствуют оба начала, и она не является исключением из общего правила, в ней также наличествует фактор эмоционального интеллекта. В связке «учитель - ученик» или «преподаватель - студент» присутствует аналогия дихотомии «руководитель - подчиненный», в этом случае имеет смысл не забывать о роли эмоционального интеллекта, который при благоприятных взаимоотношениях стимулирует образовательный процесс. В контексте положительных эмоциональных отношений растет уровень доверия и открытости со стороны субъекта обучения.

В условиях беспрестанных трансформаций, когда алгоритмы принятия решений в условиях неопределенности постоянно изменяются, наблюдается «новый всплеск внимания к субъективным, неуловимым, подразумеваемым когнитивным навыкам и возврат к анализу «многозначных» индивидуальных различий», что может помочь принятию решений в хаотичной среде. Роль интуиции, творчески парадоксальных подходов к сложным проблемам значительным образом преумножается, что свидетельствует о повышении интереса к бессознательному.

Еще в 1970-е гг. один из основоположников теории постиндустриализма Э. Тоффлер в работе «Футорошок» писал, что образование, нацеленное на перемены, является амортизатором «болезни перемен», другими словами 
именно образование есть наиболее эффективное лекарство в условиях тотальной неопределенности. Другой пророческой мыслью является суждение о том, что безграмотными в XXI веке будут не те, кто не умеет читать и писать, а те, кто не умеет учиться, разучиваться и переучиваться (Тоффлер, 1997).

К 2020 г. в активную социальную и профессиональную жизнь вступит поколение, которое принято называть поколение «WWW», или «Z», или центениалы. Для этого поколения характерны:

— погруженность в цифровой мир,

- принятие мультикультурности,

- гиперактивность,

- адблок,

- забота о собственной жизненной безопасности,

- клиповое мышление,

- визуальное восприятие информации.

Во всех этих характеристиках соединяется как сознательные установки, так и бессознательные механизмы. Уже часть этих характеристик указывает на определенную предрасположенности к творчеству. Но предрасположенность может развиться, а может остаться «спящей». В данных обстоятельствах чрезвычайно важное значение приобретает образование. В современной России данный социальный институт подвержен большим испытаниям. В обществе не утихает критика в адрес современного образования всех уровней и форм. В последнее время в Россию приезжают известные профессионалы в различных областях жизнедеятельности: от науки до бизнеса, которые выступают в роли футурологов-прорицателей.

Американский учёный японского происхождения, известный специалист в области теоретической физики, увлекающийся астрономией, активный популяризатор науки, автор научно-популярных книг и преподающий более 25 лет в нью-йоркском Сити-колледже М. Каку считает, что «мир меняется и благодаря простому росту технологических возможностей» (Какие профессии ... 2017: Электр. ресурс). Он же утверждает в своих работах, докладах и интервью, что науки и технологии будут иметь следующий вектор эволюционного развития до конца XXI и начала XXII века:

- К 2027 году станет возможным напрямую считывать из мозга воспоминания и впечатления, передавать их через Сеть и, возможно, даже загружать в мозг других людей. Это откроет путь к превращению Интернета в брейн-нет, «мозго-сеть»;

- К 2029 году роботы станут умнее людей практически во всех отношениях. Но бояться, что они отберут у нас власть, не следует. Каку считает, что у них будет «интеллект насекомых» - мощный, но направленный на решение лишь определенных типов задач, 
- К 2040-м годам нанотехнологии позволят создавать предметы из программируемой материи, которые смогут менять свою форму по приказу владельца. Возможности любой вещи, таким образом, будут ограничены только ее химическими и физическими свойствами,

- В 2050-2060-х годах начнется колонизация Марса: частные компании создадут поселения, обитатели которых смогут выживать без помощи с Земли,

- Через 100 лет Земля будет иметь общемировое правительство и общие государственные органы, чьи решения будут важнее позиции национальных властей (там же).

Другой знаковой фигурой в данном контексте является известный китайский бизнесмен Д. Ма ${ }^{1}$, основатель и председатель совета директоров компании Alibaba Group, самый богатый человек в КНР, занимающий 18 место среди самых богатейших людей в мире. Д. Ма не перестает повторять, что будущее за цифровой экономикой, построенной на цифровых технологиях.

Проверить верность предсказаний известных интеллектуалов на практике смогут только представители новых поколений, но логика развития науки и технологий, скорость ${ }^{2}$ их обновлений подсказывает, что многое, о чем говорят М. Каку и Д. Ма будет воплощено в жизнь. Они уверяют современников, что с помощью цифровых технологий можно достичь невероятных успехов, включая бессмертие.

Сегодня довольно часто обсуждаются вопросы продуктивности образования. В отмеченном контексте продуктивность связывается с заинтересованностью субъекта в получении знаний и степенью их усвоения. Проблемы продуктивности и результативности активно дебатируются внутри профессионального сообщества, на страницах научной и популярной литературы, в среде родителей, среди самих школьников и студентов, в сообществах профессионалов, в Интернет-пространстве, объединяющем более широкие заинтересованные слои общества.

\footnotetext{
${ }^{1}$ Джек Ма - первый бизнесмен с материковой части Китая, чьё фото было опубликовано на обложке журнала Forbes. По состоянию на ноябрь 2014 г., состояние Ма оценивалось компанией Bloomberg в 32,7 миллиарда долларов.

${ }^{2}$ Футуролог Рэй Курцвейл утверждает, что развитие цивилизации в XXI веке будет происходить в 5 раз быстрее, чем в XX веке. И мы пройдём технологическую фазу развития всего XX века за 20 лет. Другие западные футурологи поддерживают его мнение и считают, что технологии будут приводить к экспоненциальному развитию мира, что следующее столетие мы пройдем за семь лет. С 2014 по 2021 годы технологии изменятся в том же объёме, как они изменились в XX веке. Затем мы столетие проскочим за три года, а к концу XXI столетия, наверное, технологический цикл XX века мы будем проскакивать за месяц. И это, конечно, самый ключевой вывод, который нужно сделать (См. : Герман Греф: ... , Электр. ресурс).
} 
Научные труды Московского гуманитарного университета 2018 № 3

Со времен возникновения традиции транслировать знания человечество занимал вопрос: как сделать это наиболее эффективно? Он остается актуальным и в XXI веке. Современный субъект обучения претерпел значительные изменения под воздействием современной цивилизации, в которых акцентируются визуальная доминанта, клиповость мышления, минимизация текстов, доведенная до краткости СМС и рекламных слоганов, мозаичность впечатлений, дивергентность мышления и многое другое. Во многом это обусловлено бурным развитием информационно-коммуникационных, а теперь и цифровых технологий, привязанностью современного человека к мобильным гаджетам, новым медиа и прочим технологическим достижениям, то, что сегодня принято называть интернет-вещами. Ключевой тренд современности - технологии.

Технологии - это не только профессиональная сфера, технология это повседневная жизнь, жизнь каждого человека ${ }^{1}$. Технологии - не только уровень развития научно-технического прогресса, сегодня от них зависит мировоззрение, система ценностей, качество и уровень жизни, выбор будущей профессии, модели поведения, вкусовые и стилевые предпочтения.......

Образование сегодня испытывает разные вызовы наряду с технологиями, в частности, со стороны индустрии досуга, куда устремлены многие интересы молодого поколения, и в которых тоже во многом господствуют новые технологии. Жизнь молодого человека ежедневно требует новых эмоциональных впечатлений, часто образование в этом отношении не является конкурентоспособным, так как оно мало удивляет и поражает. Образование не может стоять в стороне от этих процессов. Оно должно быть опережающим, или хотя бы быть готовым к тем переменам, которые ему уготовлены объективными процессами развития современной цивилизации.

Однако в образовании есть фундаментальные, глубинные основания, которые не зависят от уровня развития технологий. Они не являются такими переменными, от которых имеет смысл отказываться. Внутри образования существуют составляющие, у которых могут меняться смысловые акценты, но сами они остаются незыблемыми.

В предшествующие культурно-исторические эпохи образование связывалось с рациональным началом, весьма часто в ущерб эмоциональному. В условиях избыточности информации возникает необходимость добиться баланса рационального и эмоционального, сознательного и бессознательного.

Одной из форм, отвечающей этой потребности, является занимательность, которая может базироваться на таком бессознательном качестве как

\footnotetext{
${ }^{1}$ См. видеоролик по ссылке: http://youtu.be/uEeBXUUOBiI. В диснеевском мультфильме «Город героев» в 2014 г. появился робот-диагност, способный оказать человеку первую медицинскую помощь.
} 
любопытство. Оно в любое культурно-историческое время никуда не может исчезнуть. Но в нашей культурной традиции любопытство часто интерпретируется с негативным оттенком (любопытство не порок, а большое свинство, любопытной Варваре нос оторвали...). В результате этот интерес поддерживается в исключительных случаях и для отечественной педагогики не является тотальным. Но есть и другой подход. Сэмюэл Джонсон (британский художественный критик культуры эпохи Просвещения) считал, что любопытство - одно из самых непреложных и очевидных свойств мощного интеллекта. Любопытство тесно связано с любознательностью (осознанному стремлению к знанию).

Во второй половине XX века возникло новое явление, которое в англоязычной литературе принято именовать эдьютейнментом. Эдьютейнмент сегодня представляет некую социокультурную и образовательную новацию. По сути это новая философия образования и одновременно технологии обучения. Некоторые исследователи отмечают, что практика эдьютейнмента, является производным или «побочным» продуктом от инфотейнмента (Драгун, 2015). Инфотейнмент ${ }^{1}-$ особе социокультурное явление, возникшее в результате интеграции «информации, её эстетизированных форм репрезентации и инновационных средств массовых коммуникаций» рубежа XX-XXI вв. Инфотейнмент - ответ на современный вызов цивилизации в области масс-медиа².

Эдьютейнмент соответствует запросу современного образования, в котором актуализируется интерес к выразительной формы. В выразительной форме присутствует бессознательное, как оно присутствует в эстетическом. Эдьютейнмент в силу своей природы активно заряжен синергетическим эффектом. Иначе говоря, это некий интегрированный формат подачи

${ }^{1}$ Ключевой характеристикой инфотейнмента является развлекательность, которая символизирует собой массовую культуру современности. Слово инфотейнмент слово конструктор, оно объединяет два исходных начала: «инфо» (информацию) и «тейнмент» в качестве части слова инфотейнмент, что означает в переводе с английского - развлечение.

${ }^{2}$ Инфотейнмент спровоцирован интенсивным развитием современных средств массовой информации и, прежде всего, телевидения, которое стало обрушивать на сознание современного человека огромные объемы аудиовизуальной информации, еще до появления Интернета. В ответ человек перестал их воспринимать и усваивать. Индустрия телевидения в результате этого процесса стала терпеть убытки, вызванные падением продаж рекламируемых товаров и услуг, а рекламодатели стали сокращать свои рекламные бюджеты. Нужна была технология, которая бы вернула телезрителей к экранам и в магазины. И такая технология была создана и применена. Она получила теперь уже распространенное название инфотейнмент. Именно он стал своеобразным запускным механизмом других подобных социальных практик, в том числе и эдьютейнмента. 
Научные труды Московского гуманитарного университета 2018 № 3

учебного материала, объединяющий различные современные, чаще всего интерактивные, способы, интенсифицирующие процесс усвоения знаний. В рамках этих технологий могут сочетаться теория и реальная практика, дискуссионный клуб, игровая территория, лаборатория экспериментов, brainstorm'ы, квесты, воркшопы, co-working'и, перформансы, игры живого действия, презентации и многое другое, что сегодня в ходу в различных областях человеческой деятельности, особенно у молодежи. При чем все это многообразие пропускается через призму развлекательного образования, или образовательного развлечения.

Слово эдьютейнмент образовано от двух английских слов образование - education и развлечение - entertainment. Эдьютейнмент (Хангельдиева, Богданова, 2013; White, 2003; Walldén, Soronen, 2004) - формат образовательного процесса, при котором учебный материал представлен с привлечением развлекательных методик и, зачастую, с использованием информационных технологий. Его образовательная сущность может использоваться как в официально установленных институциях обучения, так и в его неформальных, несистематизированных познавательных процесcaх, встречающихся в различных контекстах повседневности. Итальянский профессор Микела Эддис описывает эдьютейнмент как одновременное обучение и удовлетворение любопытства, ведущее к глубокому увлечению изучаемым предметом.

Существуют и другие интерпретации этого явления. Думается, что это понятие может осмысливаться двояко: в узком и широком смысле. В первом случае под эдьютейнментом изначально понимали формат телевизионных программ и программное обеспечение образовательного свойства ${ }^{1}$.

В широком смысле эдьютейнмент может трактоваться также двояко, исходя из ракурса рассмотрения. В одном случае может акцентироваться момент образования, а другой - развлечения. Первый подход осуществляется с акцентом на образовательную составляющую. Развлекательное (увлекательное) образование - это особый способ обучения, в котором профессиональная информация преподносится в яркой, занимательной и в итоге выразительной форме. Этот подход ставит акцент на получении знаний в яркой и оригинальной форме2 ${ }^{2}$ в которой усиливается элемент присут-

\footnotetext{
${ }^{1}$ Эту идею можно проиллюстрировать конкретным примером. В 1943-1945 гг. по заказу американских военно-воздушных сил США был специально создан мультипликационный фильм "PrivateSnafu" для обучения солдат. В игровых формах в фильме демонстрировались уроки по обеспечению секретности, меры предосторожности против различных заболеваний, приемы и технологии по предотвращению расовых конфликтов. Посредством развлекательного мультипликационного фильма проводилось наглядное инструктирование солдат. Этот фильм имел наивысшую популярность у солдат в течение долгого времени.

${ }^{2}$ См. видеоролик по ссылке http://www.facebook.com/mulbabar/videos/1186480868100965/ как пример эдьютеймента.
} 
ствия бессознательного за счет усиления интуитивного, эмоционального и субъективного. У наших зарубежных коллег подобное познание мира с ярко выраженной положительной эмоциональной составляющей принято называть обучением через приключение (Берджес, 2015). У нас в отечественной практике недавнего прошлого подобный подход назывался формами занимательного образования и распространялся одновременно на естественнонаучные и гуманитарные области знания (Хангельдиева, 2015).

Такой подход к образованию весьма эффективен, поэтому сегодня он широко используется в различных областях человеческой жизнедеятельности и, особенно, в бизнесе. Это связано с тем, что бизнес наиболее чувствителен к инновациям, которые способны сделать его более успешным, повысить его репутацию и имидж. Поэтому подобные форматы проведения образовательного процесса широко используются в престижных бизнес-школах мира. А сегодня, когда особый статус приобретает креативный класс, для которого формы самовыражения и самореализации, свобода творчества, психологический комфорт и передовые условия профессиональной деятельности иногда значительно важнее уровня финансового вознаграждения, то эдьютейнмент приобретает особое значение во внутрикорпоративном пространстве и сознании.

Эдьютейнмент не обязательно должен быть весёлым и развлекательным, но всегда - интересным и увлекательным. Эдьютейнмент в силу своих природных особенностей может работать в качестве терапевтического механизма для снятия страхов перед ошибкой, недоброжелательного отношения, необъективной оценки.

В России термин эдьютейнмент используется преимущественно для описания новой формы развлекательно-образовательного досуга, на которые быстрее всего откликаются современные форматы. Например, электронный ресурс «Theory\&Practice» («Теории и практики») презентуется как «платформа для обмена знаниями. Мы создаем среду для тех, кто ищет знания и хочет ими делиться». Известен образовательный проект «Арзамас» (http://arzamas.academy/), позиционирующий себя как «некоммерческий просветительский проект, посвященный гуманитарному знанию. Мы создаем для вас своеобразный университет, который соберет лучших преподавателей и будет строиться прямо у вас на глазах».

Современные технологии позволяют сделать образовательный процесс поливариантным, занимательным, эдьютейментированным, напоминающим приключение с элементами открытия.

В настоящее время известно несколько образовательных и игровых порталов, которые делают получение знаний увлекательным и занимательным. Среди них зарубежные и российские платформы и проекты. Как отмечает 
директор корпоративных образовательных программ Московской школы управления «Сколково» Павел Лукша: «...ннлайн-платформ KhanAcademy полностью перепозиционировала себя как альтернативу школьным урокам. Активно развиваются форматы школьного edutainment - от MinecraftEdu (образовательная платформа на основе популярной игры MineCraft, целевой аудиторией которой являются школьники от 8 до 14) до проектов типа Classcraft (проект, использующий механику ролевых игр для повышения интереса классов к изучению предметов). Ведущие технологические компании начинают инвестировать в новые образовательные форматы - Google выпустил решение Google.Class, a Facebook объявил о создании сети инновационных школ. Многие апологеты цифровой эры говорят о том, что современные компании будут компаниями-платформами, в частности, Г. Греф озвучил следующие ее ключевые качества:

1. Сосредоточена в облаке,

2. Достаточно безопасная,

3. Гибкая,

4. Использует In-Memory Computing (вычисление в оперативной памяти), потому что должна предоставлять услуги в миллисекунды,

5. Организована на open source - иначе устареет на следующий день после создания,

6. Использует machine learning,

7. Использует искусственный интеллект (Герман Греф: ... , Электр. ресурс).

Что касается образовательного развлечения - это форма подачи информации, созданная с развлекательной целью, с включениями обучающего компонента или проблематики из определённой области знания. Образовательное развлечение - форма и способ проведения досуга. Местом для проведения подобных проектов становится любое нетрадиционное пространство: галерея, студия, парк, музей, офис и даже кафе или ресторан. Различные интернет ресурсы ежедневно анонсирует различные образовательные события, размещает расписание их проведения в Москве, Санкт-Петербурге, Копенгагене и других городах мира. Следует отметить, что не только продвинутые неформальные группы и целевые аудитории используют данный подход, но и официальные представители различных правительственных структур. Департамент науки, промышленной политики и предпринимательства города Москвы использует формат «Научных кафе» для интенсификации обмена знаниями между ведущими научными специалистами, предпринимателями и молодежной средой. Этот формат предлагается не только в Москве, но и в регионах.

Образовательный формат вне стен традиционных институций имеет 
тенденцию к расширению. В этом отношении конкурентами школам и вузам в Москве становятся известные творческие кластеры: «Артплей», «Винзавод», «Флакон», ПRОЕКТ_FАБRИКА, «Красный Октябрь»; авангардные позиции в этом процессе можно отдать «Стрелке» (http://strelka.com/ru/idea). Доминантой ее деятельности стали именно образовательные программы. Проект превратился в открытый институт, востребованный интеллектуалами, с которым сотрудничают весьма известные и признанные западные и отечественные специалисты различных областей знаний.

Популярность приобретают различные мастер-классы по разным видам творчества, экскурсии и лекционные курсы как платные, так и бесплатные. В туристической области относительно продолжительный период времени востребованными являются «образовательные туры».

Описанное выше распространение практики интеллектуального досуга в России вызвано ростом и формированием «среднего класса», и особенно его креативного слоя. «При всех различиях сформировавшегося среднего класса, например, в США, и групп, считающихся отчасти аналогичными, например, в России или в Бразилии - у них есть значимые черты сходства. Одна из них - высокая оценка образования - и шире вложений в себя, готовность использовать в этих целях существенные ресурсы: время, деньги. Отсюда появление спроса и даже моды на «досуговое» получение дополнительного образования, в том числе - не имеющее обозримых утилитарных задач, и на интеллектуальные развлечения. Ценность праздности для некоторых социокультурных групп уступает место ценности демонстративного потребления образовательных услуг и развивающего развлечения» (Сакоян, 2011: Электр. ресурс).

Все отмеченные современные образовательные формы и форматы практически всегда включают в себя эстетический компонент. И сегодня он приобретает весьма значительный удельный вес, существенно усиливая коэффициент полезного действия, особенно это становится характерным для креативных образовательных технологий. Это особый инструмент достижения сложных целей и решения непростых задач, в которых эмоциональный компонент не является периферийным. К сожалению, в вузах это недостаточное используется и традиционное преподавание продолжает носить несколько сухой и абстрактный характер.

Одной из универсальных средств освоения действительности испокон веков является искусство. Его особая действенность определяется не столько содержанием, сколько художественно-выразительной формой. Л. С. Выготский писал, что «произведение искусства является результатом преодоления действительности художественной формой». Перефразируя его можно сказать: процесс обучения есть преодоление сложившихся в этой 
области привычных стереотипов. Преодоление стереотипов - это преодоление отрицательного бессознательного, которое при определенных обстоятельствах может становиться тормозом для движения вперед. Соотношение рационального и эмоционального, сознательного и бессознательного чувственно-конкретного и абстрактно-логического в каждом конкретном случае может быть разным. Образование будет носить творческий характер только при условии активного поиска оригинальных, эмоционально заряженных форм обучения. Форма должна удивляет, быть выразительной и запоминаемой.

Педагогический процесс - своеобразное искусство, в котором присутствует и мастерство, и артистизм, и выразительная форма подачи материала.

Эдьютейнмент теснейшим образом связан с эстетическим началом, так как он построен на продуцировании оригинальной творческой формы. Возможно, что при выстраивание новых образовательных алгоритмов нельзя забывать о роли и значении эстетического фактора и соотношении в ним сознательного и бессознательного.

\section{СПИСОК ЛИТЕРАТУРЫ}

Берджес, Д. (2015) Обучение как приключение: Как сделать уроки интересными и увлекательным. М. : Альбина Паблишер. 240 с.

Герман Греф: «Информационные технологии - отстой: будущее за экономикой данных» [Электронный ресурс] // 2035. URL: http://www. russia2035.ru/works/gref-future/ (дата обращения: 12.12.2017).

Гоулмен, Д., Бояцис, Р., МакКи, Э. (2017) Эмоциональное лидерство. Искусство управления людьми на основе эмоционального интеллекта. М.: Альпина Раблишер. 302 с.

Драгун, Е. М. (2015) Инфотейнмент как явление современной медиакультуры : дисс. .... к-та культ. М.

Какие профессии получать уже бессмысленно: Митио Каку об эволюции будущего [Электронный ресурс] // Поступи онлайн. URL: https://postupi. online/journal/lyudi-i-mnenia/kakie-professii-poluchat-uzhe-bessmyslennomitio-kaku-ob-evolyucii-budushchego/ (дата обращения: 12.12.2017).

Сакоян А. (2011) Наука без скуки [Электронный ресурс] // Полит.Ру. URL: http://polit.ru/article/2011/07/29/edutainment/ (дата обращения: 12.12.2017).

Тофлерр, Э. (1997) Футорошок / пер. с англ. СПб. : Лань. 464 с.

Хангельдиева, И. Г. (2015) Эстетические аспекты образовательного процесса // VII Овсянниковская международная эстетическая конференция «Felix Aestheticus: гуманитарная миссия эстетики». М. : 000 Издательство «Согласие». С. 105-114. 
Хангельдиева, И. Г., Богданова, Е. М. (2013) Эдьютейнмент: от телевизионного формата до современных социальных и образовательных // Культура и образование в современном обществе: стратегии развития и сохранения: сб. науч. ст. по матер. всеросс. науч. конфер. междунар. участ. / отв. ред. Т. В. Коваленко; редкол. И. И. Горлова, В. Е. Науменко, Н. А. Костина. Краснодар: 000 Экоинвест. С. 190-201.

Walldén, S., Soronen, A. (2004) Edutainment. From Television and Computers to Digital Television. May.

White, R. (2003) That is Edutainment. White Hutchinson Leisure \& Learning Group.

Дата поступления: 30.12.2017 2.

Хангельдиева Ирина Георгиевна - доктор философских наук, профессор; профессор кафедры истории и философии образования педагогического факультета Московского государственного университета имени М. В. Ломоносова; действительный член Международной академии информатизации и Международной академии высшей школы. Адрес: 119991, Россия, г. Москва, Ленинские горы, мкр. 1, стр. 52 . Тел.: Тел.: +7 (495) 939-32-81. Эл. адрес: irkhang@gmail.com

Khangeldiyeva Irina Georgiyevna, Doctor of Philosophy, Professor, Professor, Department of History and Philosophy of Education, Faculty of Educational Studies, Lomonosov Moscow State University; Full Member, International Informatisation Academy, International Higher Education Academy. Postal address: Bldg. 52, Residential Estate 1, Leninskie Gory, Moscow, Russian Federation, 119991. Tel.: +7 (495) 939-32-81. E-mail: irkhang@gmail.com

\section{Для цитирования:}

Хангельдиева И. Г. Эдьютейнмент как единство сознательного и бессознательного [Электронный ресурс] // Научные труды Московского гуманитарного университета. 2018. № 3. URL: http://journals.mosgu.ru/trudy/article/ view/742 (дата обращения: дд.мм.гг.). DOI: 10.17805/trudy.2018.3.5 